\title{
Sensor Applications in Agrifood Systems: Current Trends and Opportunities for Water Stewardship
}

\author{
Naoum Tsolakis ${ }^{1, *(\mathbb{C} \text {, Eirini Aivazidou }}{ }^{2,3}$ ) and Jagjit Singh Srai ${ }^{1}$ \\ 1 Centre for International Manufacturing, Institute for Manufacturing (IfM), Department of Engineering, \\ School of Technology, University of Cambridge, Cambridge CB3 0FS, UK; jss46@eng.cam.ac.uk \\ 2 Department of Computer Science and Engineering (DISI), School of Engineering, \\ Alma Mater Studiorum-University of Bologna, 40126 Bologna, Italy; eirini.aivazidou@unibo.it \\ 3 Laboratory of Statistics and Quantitative Analysis Methods (LASCM), Division of Industrial Management, \\ Department of Mechanical Engineering, Aristotle University of Thessaloniki, 54124 Thessaloniki, Greece; \\ aveirini@auth.gr \\ * Correspondence: nt377@cam.ac.uk
}

Received: 6 February 2019; Accepted: 16 March 2019; Published: 20 March 2019

\begin{abstract}
Growing global food demand and security concerns dictate the need for state-of-the-art food production technologies to increase farming efficiency. Concurrently, freshwater overexploitation in agriculture, especially in arid and water-scarce areas, emphasises the vital role of appropriate water-saving irrigations techniques to ensure natural resources sustainability in food supply networks. In line with the development of automated systems, the use of sensors for water monitoring, indicatively in the cases of smart farming or precision agriculture, could further promote the preservation of freshwater resources. To this end, this research first provides a review of sensor applications for improving sustainability in agrifood systems. We then focus on digital technologies applied for monitoring and assessing freshwater utilisation in the food commodities sector based on academic literature and real-world business evidence. A contextual map is developed for capturing the main technical, environmental and economic factors affecting the selection of sensors for water monitoring and stewardship during agricultural production. This first-effort framework, in terms of sensor-based freshwater monitoring, aims at supporting the agrifood system's decision makers to identify the optimal sensor applications for improving sustainability and water efficiency in agricultural operations.
\end{abstract}

Keywords: sensor application; agrifood system; food supply network; freshwater monitoring; water stewardship

\section{Introduction}

Sustainability and resources stewardship in the agrifood sector have emerged as critical research topics in management science, considering the increasing global population and associated elevated nutritional needs [1], along with the intensifying anthropogenic activity in the international business landscape that raises societal and organisational competition over the scarce natural resources [2]. In particular, during the last 50 years, a three-fold increase in global dietary needs has been observed, while resources' appropriation exceeds by $30 \%$ nature's capability to regenerate [3]. Agriculture impacts heavily freshwater resources, as the sector consumes and pollutes nearly $70 \%$ of the global freshwater reserves [4]. Furthermore, approximately one third of all food produced worldwide is lost or wasted [5] across end-to-end food supply network operations [6]. To this end, the resulting need to replenish discarded food supplies intensifies freshwater appropriation both directly and indirectly [7].

Academic literature is being proliferated by studies identifying information and data elements necessary for conducting end-to-end food supply network modelling and analyses [8]; stakeholders 
can then make informed decisions regarding natural resources' stewardship for promoting sustainability [9]. However, a lack of emphasis on the management of freshwater resources from a holistic supply chain perspective is evident in the literature [10]. In addition, to the best of our knowledge, only a limited number of studies has a pragmatic view over the technical ability to monitor the freshwater needs of crops and acquire data for guiding real-time precision farming and irrigation operations. In particular, efficiency in irrigation operations is deemed critical, due both to the variability of weather and climate conditions and to the farmers' limited capacity in accessing understandable agrometeorological information [11]. Increased awareness and real-time visibility of agro-field water needs could thus assist farmers in obtaining the benefits of freshwater resource management interventions (e.g., water-efficient irrigation, wastewater recycling and reuse, prudent use of fertilisers/pesticides [10]) and thus planning to increase productivity and mitigate regional water scarcity. In addition, recent evidence argues that ensuring freshwater sustainability could support the financial performance of agrifood supply networks in environmentally aware markets [12].

In this regard, the processes of digitalisation and traceability in food supply networks via sensor-driven operations could assist in promoting eco-sustainability [13]. Furthermore, due to the biological nature of food commodities, near-real-time traceability and tracing of distribution and storage conditions, food degradation effects and quality attributes, via sensory applications, could further foster consumers' trust [14].

In fact, sensors are deemed to be appropriate applications for monitoring occurrences of unexpected events and conditions that could affect the perishability of food product flows across supply networks, hence timely informing about actions for mitigating any associated risks. Typical data and information captured through sensors about warehouses, vehicles and containers used in food supply chains operations include [15]: (i) environmental conditions (i.e., temperature, humidity, concentration of $\mathrm{CO}_{2}$ ); (ii) states of motion (i.e., irregular vibrations, unanticipated falls, inordinate tilt, illegal opening) and (iii) geographical location. Notably, temperature mismanagement during transportation may result in food quality decay and product losses of about 35\% [16], while transport vibrations and shocks could severely compromise integrity and quality in particular of food products like fruits and vegetables [17].

Regarding water management in agricultural systems, the use of sensors to determine the water needs of crops compared to classical sampling-based techniques is recommended, as their application: (i) saves time; (ii) is not laborious and (iii) is feasible for large-scale farming [18]. These sensors can either be deployed at field/soil for informing intelligent irrigation systems [19] or be mounted on automated guided vehicles that perform farming operations to recognise the specific freshwater requirements of individual plants [20].

Overall, this research effort contributes towards providing a first 'mapping' of the existent sensors utilised for efficient freshwater monitoring or related operations to support decision makers in identifying the optimal automation-related solutions for promoting sustainable water management during agricultural processes. The remainder of the paper is structured as follows. In Section 2, a review of sensor applications across food supply chains is presented. In Section 3, emphasis is placed on commercial sensor applications for enhancing water stewardship in agrifood systems, through summarising the main types of sensors and related information. Finally, in Section 4, we conclude with the major insights and recommendations for future research.

\section{Sensor-Focused Decision Making in Food Supply Networks}

As empirical research argues that the perception of farmers about precipitation and temperature variability could affect the related adaptation strategies implemented [21], the use of sensors for real-time monitoring in agriculture emerges as an essential precondition for effective decision making. In addition, the perishable nature of food products, along with the variability of preservation, packaging and transportation conditions, impacts the products' remaining shelf life [22], further highlighting the catalytic role of sensor applications for the monitoring of food attributes and 
environmental conditions. To that end, sensors can be used not only to enable visibility during agricultural production, but also to provide end-to-end traceability in food supply chains, particularly in the case of cold chains [23]. The retrieved data and information could inform efficient and responsive supply chain management interventions to mitigate food safety risks, improve inventory management, reduce waste and losses, as well as allow for dynamic pricing systems [24]. Recently, due to the improvement, accuracy, technical feasibility and economic viability of sensors, the use of wireless sensor networks in the agricultural sector is becoming the norm [25]. Indicatively, the use of wireless multi-sensor networks is utilised in the case of honey peach export chains to prevent unexpected food quality losses and to ensure transparency [26]. Ruiz-Garcia et al. [27] provided a review of sensor technologies applicable to the agriculture and food industry. Notwithstanding the enabling role of sensors towards sustainable food networks, their adoption and implementation by end-to-end food supply chains requires a robust decision-making process; Óskarsdóttir and Oddsson [23] provide a detailed decision-support framework for guiding stakeholders in cold food chains to identify appropriate traceability technology.

Sensor applications can foster proactive decision making in agrifood supply chains. Contò et al. [28] discussed the need for agricultural innovation and technology transfer from research organizations to multi-tier agro-system stakeholders, focusing on the Apulia region, Italy. The authors supported the traceability and certification of agrifood products, enabled by sensor-based RFID technology for ensuring efficient logistics operations and offering high quality, environmentally friendly and cost-effective agro-product flows. Li and Wang [29] proposed a dynamic pricing model, based on fresh vegetable predicted shelf life enabled by sensor-captured data, in a chilled food retail network in the UK. The provided analytical and simulation results encourage food companies to adopt data gathering and analysis related innovations to foster their competitiveness. Furthermore, Tamplin [30] discussed the need of integrating sensors and predictive models for monitoring alterations in food quality attributes across end-to-end food supply networks to mitigate the risk of food-borne illnesses and commodities' spoilage. The author described cases from the seafood and meat supply networks highlighting the 'Pathways to Market' project that facilitates digital information to increase the sales and value of Tasmanian food products. Wang et al. [26] deployed a real-time system for monitoring transport and storage conditions in perishable food supply chains via applying the ZigBee-standard wireless sensor network. The results highlight the feasibility of such systems in terms of both performance (e.g., high success data transmission rate of $99 \%$ ) and viability (e.g., sufficient life time in terms of power consumption). Finally, Moharana and Dutta [31] examined alternative vegetation water indices to investigate the water stress variability in paddy rice agriculture in India during the pre-monsoon and monsoon seasons. Predictive models of leaf relative water content use data and imagery captured through both portable spectroradiometer and the Hyperion sensor on board the Earth Observing-1 satellite, respectively. Table 1 summarises the key decisions related to the application of sensor in food supply networks, as identified in peer-reviewed scientific articles, along with the targeted aims.

Table 1. Sensor-related decisions in food supply networks.

\begin{tabular}{|c|c|c|}
\hline Reference & Sensor-Related Decisions & Supply Network Aim \\
\hline Contò et al. [28] & $\begin{array}{l}\text { - } \quad \text { Create networks stressing multi-level stakeholders behaviours. } \\
\text { - } \quad \text { innilitate the transfer of knowledge from research and agricultural } \\
\text { - } \quad \text { Structure the portfolio of technologies and technology scouting activities. } \\
\text { - } \quad \text { Analyse the innovation needs. } \\
\text { - } \quad \text { Establish patterns of technology transfer. }\end{array}$ & $\begin{array}{ll}\text { - } & \text { Quality } \\
\text { - } & \text { Food safety }\end{array}$ \\
\hline Li and Wang [29] & $\begin{array}{l}\text { - Decide on the information to be monitored (e.g., product identity, product } \\
\text { batch/package identity, location, period of time at each } \\
\text { location, temperature). } \\
\text { - } \quad \text { Develop dynamic food pricing model related to remaining shelf-life and } \\
\text { based on demand response. } \\
\text { - } \quad \text { Allow real-time data gathering and analytics. } \\
\text { - Articulate demand scenarios based on food pricing and shelf life. }\end{array}$ & $\begin{array}{ll}\text { - } & \text { Dynamic pricing } \\
\text { - } & \text { Quality } \\
\text { - } & \text { Shelf life }\end{array}$ \\
\hline
\end{tabular}


Table 1. Cont.

\begin{tabular}{|c|c|c|}
\hline Reference & Sensor-Related Decisions & Supply Network Aim \\
\hline Tamplin [30] & $\begin{array}{l}\text { - Adopt predictive microbiology models for describing changes in food } \\
\text { quality as a function of environmental conditions. }\end{array}$ & $\begin{array}{ll}- & \text { Quality } \\
\text { - } & \text { Food safety }\end{array}$ \\
\hline Wang et al. [26] & $\begin{array}{l}\text { - Decide on the architecture of the wireless sensor network, if applied. } \\
\text { - Decide on the topology of a wireless sensor network, if applied. } \\
\text { - Decide on the hardware and software implementation of the wireless } \\
\text { sensor network, if applied. }\end{array}$ & $\begin{array}{ll}- & \text { Quality } \\
- & \text { Shelf life }\end{array}$ \\
\hline $\begin{array}{l}\text { Moharana and } \\
\text { Dutta [31] }\end{array}$ & $\begin{array}{l}\text { - Decide on the wavelength range that potential optical sensors need } \\
\text { to detect. } \\
\text { Decide on the indices that need to be calculated for describing } \\
\text { agricultural water status. } \\
\text { - Decide on the algorithms and models to calculate indices. }\end{array}$ & $\begin{array}{ll}- & \text { Water content } \\
- & \text { Water stress }\end{array}$ \\
\hline
\end{tabular}

\section{Sensor Applications for Water Stewardship in Agrifood Systems}

Focusing on freshwater resources, spatial and temporal climatic changes, as well as uncertainties in weather conditions, can affect freshwater allocation [32]. Thus, the use of sensors during agricultural production can efficiently monitor soil moisture and water content, allowing for proactive decisions regarding irrigation and fertilisation operations [25]. Wireless sensor networks are the norm in agricultural production systems to monitor field conditions, water utilisation and climate variability, aiming to enable decision support systems regarding the scheduling of irrigation operations and the determination of individual plants' water requirements [33].

Indicatively, Sánchez-Molina et al. [34] studied alternative virtual sensors for designing irrigation controllers for tomatoes in coconut coir substrate in Almería, Spain, that elaborate data over the amount of water in three crop levels, namely: substrate, root and aerial part (including leaves, stems and fruit). Moharana and Dutta [31] used optical sensors for the evaluation of indices related to the leaf relative water content and growth of rice in India. Incrocci et al. [35] demonstrated the use of dielectric sensors and probes for controlling irrigation and fertigation of container ornamental nursery stocks in Pistoia, Italy, primarily irrigated via urban and peri-urban wastewater. The study results demonstrated freshwater savings of more than $50 \%$, depending on the ornamental species. In addition, Fourati et al. [36] developed a web-based decision support system, enabled by a wireless sensor network, for monitoring evapotranspiration, rain water levels and soil moisture to support efficient irrigation scheduling for olive fields in Tunisia. Nolz [37] supported the use of a wireless network combining different sensor types to enable integrated water management in agriculture through real-time data monitoring. The author stressed the importance of calibrating weighing lysimeters and soil water sensors to directly quantify evapotranspiration, precipitation and soil water content for the accurate assessment of soil water balance.

Regarding the extended food supply networks, Wang et al. [26] deployed a wireless sensor network for the real-time monitoring of a perishable food chain and highlighted the need to meticulously configure both software and hardware system components to achieve technical viability and a successful data communication rate. Table 2 summarises the sensors used in real-world agrifood supply network operations, along with the parameters and monitored unit, that could enhance water stewardship.

Table 2. Categorization of sensors for water stewardship.

\begin{tabular}{llll}
\hline Monitored Parameter & Monitored Unit & Water Monitoring & References \\
\hline Evapotranspiration & Crop & Direct & Sánchez-Molina et al. [34]; Incrocci et al. [35]; Fourati et al. [36]; Nolz [37] \\
\hline Precipitation & Crop & Direct & Fourati et al. [36]; Nolz [37] \\
\hline Soil Moisture Content & Crop & Direct & Sánchez-Molina et al. [34]; Fourati et al. [36]; Nolz [37] \\
\hline Leaf Water Content & Crop & Direct & Mohara and Dutta [31]; Sánchez-Molina et al. [34] \\
\hline Temperature & Vehicle; warehouse & Indirect & Wang et al. [26] \\
\hline Humidity & Vehicle; warehouse & Indirect & Wang et al. [26] \\
\hline $\mathrm{CO}_{2}$ Concentration & Vehicle; warehouse & Indirect & Wang et al. [26] \\
\hline
\end{tabular}


Although the majority of sensors directly monitor water-related parameters in the crop field, such as evapotranspiration, precipitation, soil or leaf water content, other sensor applications could further support water management though monitoring parameters which are indirectly related to freshwater resources. Indicatively, monitoring the temperature or humidity in a fresh commodity warehouse reduces the risk of food waste [24], which otherwise could lead to further food production requiring additional freshwater resources [38]. Figure 1 provides a graphical representation of a sensor-based system for enabling water monitoring in agrifood supply networks.

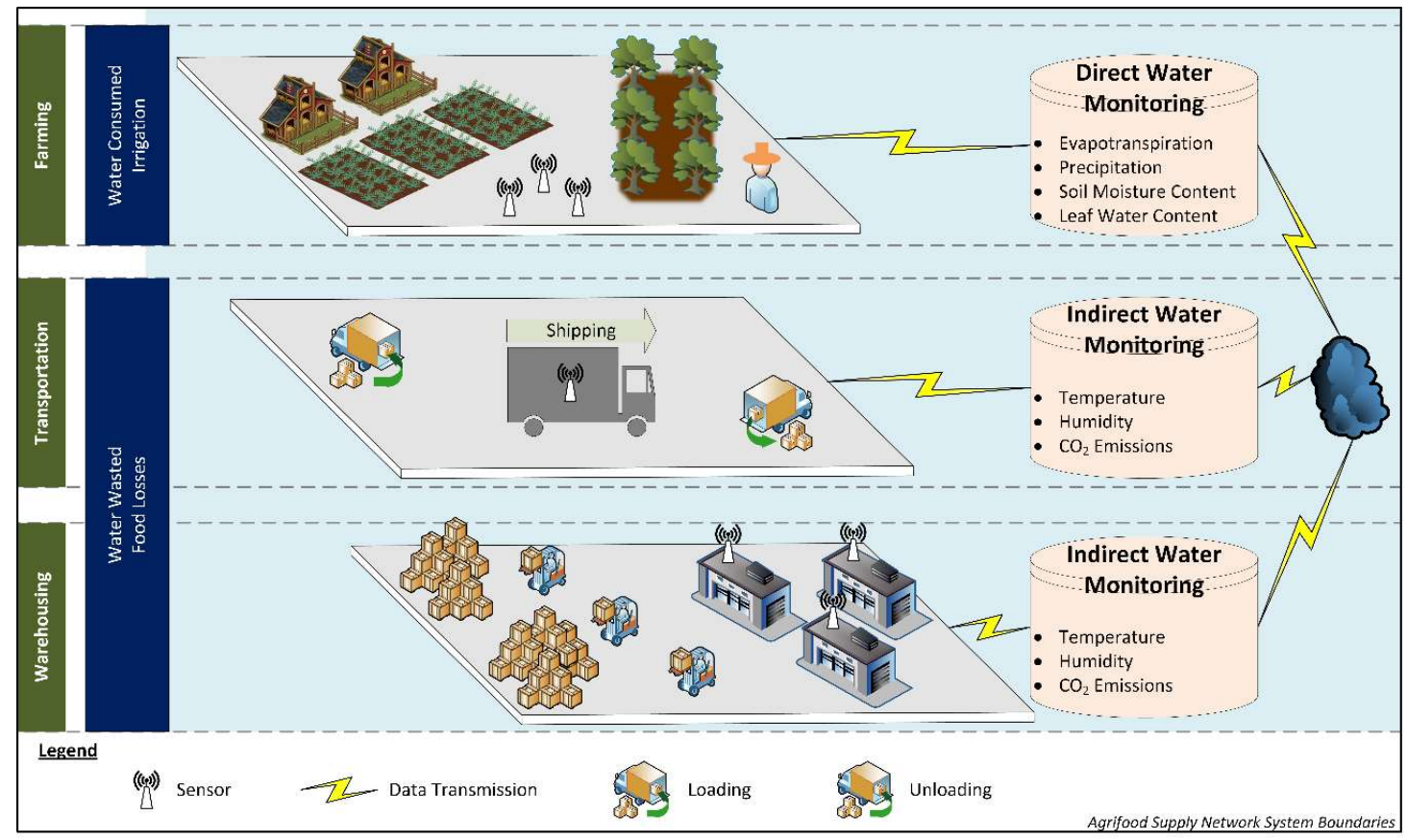

Figure 1. Sensor-based system for water monitoring in agrifood sytems.

\section{Discussion}

Technological advancements in the automation field allow for real-time environment sensing and data processing, thus allowing for increased responsiveness and enhanced resilience. In the agrifood sector, regardless of the size of the agricultural fields, the use of sensor-driven operations could further promote food security [39], which constitutes an emerging challenge for both developing and developed nations.

Although sensor applications for directly monitoring freshwater resources have been limited up until now, this paper constitutes a first research effort towards identifying the existing types of sensors that can be used in agrifood supply operations to support decision-making processes around automated-driven water stewardship. We envision that this work could encourage: (i) farming practitioners to apply sensor applications for efficient freshwater monitoring and management, indicatively in the case of container nursery crops (i.e., plants grown in containers in soilless substrates), to cultivate food commodities in water-scarcity-prone areas, and (ii) all stakeholders to develop a holistic sensor-based system for monitoring freshwater and other relevant parameters across end-to-end food supply networks.

Future research should investigate the ramifications of sensor applications on managing water use from a food systems perspective, as potential rebound effects fostering the expansion of the total irrigated area and associated agricultural operations could arise; hence, water consumption would be increased due to the higher irrigation requirements [40]. Finally, application of sensors for enabling water monitoring in meat-based human food [41], or even animal food [42], supply 
networks could further provide meaningful insights on the sustainable use of freshwater resources in the water-intensive livestock industry.

Author Contributions: Conceptualisation, N.T.; writing-original draft preparation, N.T. and E.A.; writing — review and editing, E.A.; supervision and funding acquisition, J.S.S.

Funding: This research has received funding from: (i) the Biotechnology and Biological Sciences Research Council (BBSRC) under Reference No. BB/P027970/1, Project Title: “Transforming India's Green Revolution by Research and Empowerment for Sustainable food Supplies", and (ii) the European Institute of Innovation \& Technology Food (EIT Food) under Activity Code 19041, Project Title: "The development of organic supply chains that drive fair, transparent and healthy options for the consumer".

Conflicts of Interest: The authors declare no conflict of interest.

\section{References}

1. The State of Food and Agriculture 2018-Migration, Agriculture and Rural Development. Available online: http:/ / www.fao.org/3/I9549EN/i9549en.pdf (accessed on 9 January 2019).

2. Aivazidou, E.; Tsolakis, N.; Vlachos, D.; Iakovou, E. Water footprint management policies for agrifood supply chains: A critical taxonomy and a system dynamics modelling approach. Chem. Eng. Trans. 2015, 43, 115-120.

3. Staniškis, J.K. Sustainable consumption and production: How to make it possible. Clean Technol. Environ. 2012, 14, 1015-1022. [CrossRef]

4. Water Uses, AQUASTAT. Available online: www.fao.org/nr/water/aquastat/water_use/index.stm (accessed on 9 January 2019).

5. Global Food Losses and Food Waste-Extent, Causes and Prevention. Available online: http://www.fao. org/3/a-i2697e.pdf (accessed on 9 January 2019).

6. Govindan, K. Sustainable consumption and production in the food supply chain: A conceptual framework. Int. J. Prod. Econ. 2018, 195, 419-431. [CrossRef]

7. Wunderlich, S.M.; Martinez, N.M. Conserving natural resources through food loss reduction: Production and consumption stages of the food supply chain. Int. Soil Water Conserv. Res. 2018, 6, 331-339. [CrossRef]

8. Tsolakis, N.K.; Keramydas, C.A.; Toka, A.K.; Aidonis, D.A.; Iakovou, E.T. Agrifood supply chain management: A comprehensive hierarchical decision-making framework and a critical taxonomy. Biosyst. Eng. 2014, 120, 47-64. [CrossRef]

9. Accorsi, R.; Cholette, S.; Manzini, R.; Tufano, A. A hierarchical data architecture for sustainable food supply chain management and planning. J. Clean. Prod. 2018, 203, 1039-1054. [CrossRef]

10. Aivazidou, E.; Tsolakis, N.; Iakovou, E.; Vlachos, E. The emerging role of water footprint in supply chain management: A critical literature synthesis and a hierarchical decision-making framework. J. Clean. Prod. 2016, 137, 1018-1037. [CrossRef]

11. Culman, M.; de Farias, C.M.; Bayona, C.; Cabrera Cruz, J.D. Using agrometeorological data to assist irrigation management in oil palm crops: A decision support method and results from crop model simulation. Agric. Water Manag. 2019, 213, 1047-1062. [CrossRef]

12. Aivazidou, E.; Tsolakis, N.; Vlachos, D.; Iakovou, E. A water footprint management framework for supply chains under green market behaviour. J. Clean. Prod. 2018, 197, 592-606. [CrossRef]

13. Papetti, A.; Marconi, M.; Rossi, M.; Germani, M. Web-based platform for eco-sustainable supply chain management. Sustain. Prod. Consum. 2019, 17, 215-228. [CrossRef]

14. Galvez, J.F.; Mejuto, J.C.; Simal-Gandara, J. Future challenges on the use of blockchain for food traceability analysis. Trends Analyt. Chem. 2018, 107, 222-232. [CrossRef]

15. Wang, X.; Fu, D.; Fruk, G.; Chen, E.; Zhang, X. Improving quality control and transparency in honey peach export chain by a multi-sensors-managed traceability system. Food Control 2018, 88, 169-180. [CrossRef]

16. Zöller, S.; Wachtel, M.; Knapp, F.; Steinmetz, R. Going all the way-Detecting and transmitting events with wireless sensor networks in logistics. In Proceedings of the 8th IEEE Workshop on Practical Issues in Building Sensor Network Applications, Sydney, Australia, 21-24 October 2013.

17. Paternoster, A.; Vanlanduit, S.; Springael, J.; Braet, J. Vibration and shock analysis of specific events during truck and train transport of food products. Food Packag. Shelf 2018, 15, 95-104. [CrossRef] 
18. Lea-Cox, J.D.; Bauerle, W.L.; van Iersel, M.W.; Kantor, G.F.; Bauerle, T.L.; Lichtenberg, E.; King, D.M.; Crawford, L. Advancing wireless sensor networks for irrigation management of ornamental crops: An overview. HortTechnology 2013, 23, 717-724. [CrossRef]

19. Goap, A.; Sharma, D.; Shukla, A.K.; Krishna, C.R. An IoT based smart irrigation management system using Machine learning and open source technologies. Comput. Electron. Agric. 2018, 155, 41-49. [CrossRef]

20. Bechtsis, D.; Tsolakis, N.; Vlachos, D.; Srai, J.S. Intelligent Autonomous Vehicles in digital supply chains: A framework for integrating innovations towards sustainable value networks. J. Clean. Prod. 2018, 181, 60-71. [CrossRef]

21. Allahyari, M.S.; Ghavami, S.; Masuleh, Z.D.; Michailidis, A.; Nastis, S.A. Understanding farmers' perceptions and adaptations to precipitation and temperature variability: Evidence from Northern Iran. Climate 2016, 4, 58. [CrossRef]

22. De Marco, I.; Iannone, R. Production, packaging and preservation of semi-finished apricots: A comparative Life Cycle Assessment study. J. Food Eng. 2017, 206, 106-117. [CrossRef]

23. Óskarsdóttir, K.; Oddsson, G.V. Towards a decision support framework for technologies used in cold supply chain traceability. J. Food Eng. 2019, 240, 153-159. [CrossRef]

24. Mercier, S.; Uysal, I. Neural network models for predicting perishable food temperatures along the supply chain. Biosyst. Eng. 2018, 171, 91-100. [CrossRef]

25. Aqeel-Ur-Rehman; Abbasi, A.Z.; Islam, N.; Shaikh, Z.A. A review of wireless sensors and networks' applications in agriculture. Comput. Stand. Interfaces 2014, 36, 263-270. [CrossRef]

26. Wang, J.; Wang, H.; He, J.; Li, L.; Shen, M.; Tan, X.; Min, H.; Zheng, L. Wireless sensor network for real-time perishable food supply chain management. Comput. Electron. Agric. 2015, 110, 196-207. [CrossRef]

27. Ruiz-Garcia, L.; Lunadei, L.; Barreiro, P.; Robla, J.I. A review of wireless sensor technologies and applications in agriculture and food industry: State of the art and current trends. Sensors 2009, 9, 4728-4750. [CrossRef] [PubMed]

28. Contò, F.; Faccilongo, N.; Dicecca, R.; Zaza, C.; La Sala, P. An innovative sensor in the agro-food supply Chain: A RFID technology model. CEUR Workshop Proc. 2015, 1498, 624-635.

29. Li, D.; Wang, X. Dynamic supply chain decisions based on networked sensor data: An application in the chilled food retail chain. Int. J. Prod. Res. 2017, 55, 5127-5141. [CrossRef]

30. Tamplin, M.L. Integrating predictive models and sensors to manage food stability in supply chains. Food Microbiol. 2018, 75, 90-94. [CrossRef]

31. Moharana, S.; Dutta, S. Estimation of water stress variability for a rice agriculture system from space-borne hyperion imagery. Agric. Water Manag. 2019, 213, 260-269. [CrossRef]

32. Withanachchi, S.S.; Köpke, S.; Withanachchi, C.R.; Pathiranage, R.; Ploeger, A. Water resource management in dry zonal paddy cultivation in mahaweli river basin, Sri Lanka: An analysis of spatial and temporal climate change impacts and traditional knowledge. Climate 2014, 2, 329-354. [CrossRef]

33. Ojha, T.; Misra, S.; Raghuwanshi, N.S. Wireless sensor networks for agriculture: The state-of-the-art in practice and future challenges. Comput. Electron. Agric. 2015, 118, 66-84. [CrossRef]

34. Sánchez-Molina, J.A.; Rodríguez, F.; Guzmán, J.L.; Ramírez-Arias, J.A. Water content virtual sensor for tomatoes in coconut coir substrate for irrigation control design. Agric. Water Manag. 2015, 151, 114-125. [CrossRef]

35. Incrocci, L.; Marzialetti, P.; Incrocci, G.; Di Vita, A.; Balendonck, J.; Bibbiani, C.; Spagnol, S.; Pardossi, A. Sensor-based management of container nursery crops irrigated with fresh or saline water. Agric. Water Manag. 2019, 213, 49-61. [CrossRef]

36. Fourati, M.A.; Chebbi, W.; Kamoun, A. Development of a web-based weather station for irrigation scheduling. In Proceedings of the 3rd International Colloquium in Information Science and Technology (CIST), Tetouan, Morocco, 20-22 October 2014.

37. Nolz, R. A review on the quantification of soil water balance component as a basis for agricultural water management with a focus on weighing lysimeters and soil water sensors. Bodenkultur 2016, 67, 133-144.

38. Ridoutt, B.G.; Juliano, P.; Sanguansri, P.; Sellahewa, J. The water footprint of food waste: Case study of fresh mango in Australia. J. Clean. Prod. 2010, 18, 1714-1721. [CrossRef]

39. Tsolakis, N.; Srai, J.S. A System Dynamics approach to food security through smallholder farming in the UK. Chem. Eng. Trans. 2017, 57, 2023-2028. 
40. Geng, Q.; Ren, Q.; Nolan, R.H.; Wu, P.; Yu, Q. Assessing China's agricultural water use efficiency in a green-blue water perspective: A study based on data envelopment analysis. Ecol. Ind. 2019, 96, 329-335. [CrossRef]

41. Tsolakis, N.; Srai, J.S.; Aivazidou, E. Blue Water Footprint Management in a UK Poultry Supply Chain under Environmental Regulatory Constraints. Sustainability 2018, 10, 625. [CrossRef]

42. Aivazidou, E.; Tsolakis, N. Assessing the water footprint of pets: The case of small breed dogs. Chem. Eng. Trans. 2017, 57, 517-522.

(C) 2019 by the authors. Licensee MDPI, Basel, Switzerland. This article is an open access article distributed under the terms and conditions of the Creative Commons Attribution (CC BY) license (http:/ / creativecommons.org/licenses/by/4.0/). 